\title{
Comparação de diferentes protocolos para a deteç̧ão do vírus da diarréia viral bovina por RT-PCR em grupos de sangue total e de soro sangǘneo, artificialmente contaminados
}

\author{
Comparison of different protocols for the bovine viral diarrhea virus \\ detection by RT-PCR in pools of whole blood and blood serum \\ artificially contaminated
}

\author{
Daniela Pilz ${ }^{1}$; Alice F. Alfieri²; Amauri A. Alfieri ${ }^{2 *}$
}

Resumo

\begin{abstract}
A técnica da RT-PCR foi otimizada e avaliada para a deteç̧ão da região 5 ' terminal não-traduzida do genoma do vírus da diarréia viral bovina (BVDV) em amostras clínicas de bovinos, constituídas por soro sangüíneo e sangue total, artificialmente contaminadas com a estirpe NADL do BVDV. Para a otimização da técnica foram avaliados: i) dois pares de primers, 103 / 372 (WEINSTOCK et al., 2001) e 324 / 326 (VILCEK et al., 1994) ii) quatro métodos de extração do ácido nucléico (fenol / clorofórmio / álcool isoamílico; sílica / isotiocianato de guanidina; uma combinação dos dois métodos anteriores e TRIzol ${ }^{\mathrm{TM}}$ ) e iii) diferentes concentrações e composições de reagentes, tampões e tempo/temperatura das reações. Entre todas as alternativas testadas a que resultou na amplificação de um produto com 290 pb, que foi facilmente visualizado em gel de agarose $2 \%$ com brometo de etídeo, foi a que empregou as seguintes condições: i) primers 103 e 372; ii) volume inicial e amostra clínica: $50 \mathrm{~mL}$ de soro sangüíneo; iii) extração do ácido nucléico: método da sílica / isotiocianato de guanidina, iv) transcrição reversa: $9 \mathrm{~mL}$ do ácido nucléico extraído, 1xPCR buffer (20 mM Tris- $\mathrm{HCl} \mathrm{pH} \mathrm{8,4} \mathrm{e} 50 \mathrm{mM} \mathrm{KCl}), 1,5 \mathrm{mM} \mathrm{MgCl}_{2}, 60$ unidades da enzima transcriptase reversa M-MLV, desnaturação do RNA a $97^{\circ} \mathrm{C} / 4$ min e transcrição reversa a $42^{\circ} \mathrm{C} /$ 30 min e v) PCR: primers $103 / 372$ com temperatura de anelamento de $59^{\circ} \mathrm{C}$. A utilização da RT-PCR nas condições otimizadas nesse estudo possibilitou a amplificação da estirpe NADL do BVDV $\left(10^{3,56} \mathrm{TCID}_{50}\right)$ em pools, artificialmente contaminados, de soro sangüíneo de bovinos até a diluição de 1:160.
\end{abstract}

Palavras-chaves: Bovino, diarréia viral bovina, BVDV, RT-PCR, soro sangüíneo

1 Aluna do Programa de Pós-graduação em Ciência Animal (Área de Concentração: Sanidade Animal; Nível: Mestrado), Centro de Ciências Agrárias (CCA), Universidade Estadual de Londrina (UEL).

2 Laboratório de Virologia Animal, Departamento de Medicina Veterinária Preventiva, CCA, UEL, Campus Universitário, caixa postal 6001, CEP. 86051-990, Londrina, Paraná, Brasil.

* Autor para correspondência E-mail: alfieri@uel.br 


\begin{abstract}
The RT-PCR technique was optimized and evaluated to detect the 5' untranslated region of bovine viral diarrhea virus (BVDV) from clinical samples that consisted of blood serum and whole blood artificially contaminated with the NADL strain of BVDV. To optimization of technique, the following conditions were evaluated: i) two pairs of primers, $103 / 372$ (WEINSTOCK et al., 2001) and 324 / 326 (VILCEK et al., 1994), ii) four methods of nucleic acid extraction (phenol/chloroform/isoamyl alcohol; silica/guanidine isothiocyanate; a combination of the two previous methods; and TRIzol ${ }^{\mathrm{TM}}$ ) and iii) different concentrations and compositions of reagents and time/temperature of the reactions. Between the alternatives tested that resulted in the amplification of the 290 bp product that was easily visualized in ethidium bromide stained 2\% agarose gel was that presented the following conditions: i) primers 103 and 372; ii) initial volume and clinical sample: $50 \mathrm{~mL}$ of blood serum; iii) extraction of nucleic acid: silica/guanidine isothiocyanate method; iv) reverse transcription: $9 \mathrm{~mL}$ extracted nucleic acid, 1xPCR buffer ( $20 \mathrm{mM}$ Tris$\mathrm{HCl} \mathrm{pH} 8.4$ and $50 \mathrm{mM} \mathrm{KCl}), 1.5 \mathrm{mM} \mathrm{MgCl}_{2} ; 60$ units of reverse transcriptase enzyme M-MLV, RNA denaturation at $97^{\circ} \mathrm{C} / 4 \mathrm{~min}$, and reverse transcription at $42^{\circ} \mathrm{C} / 30 \mathrm{~min}$; v) PCR: primers 103 / 372 with anneling temperature at $59^{\circ} \mathrm{C}$. The utilization of RT-PCR within these optimized conditions allowed the amplification of the BVDV NADL strain $\left(10^{3,56} \mathrm{TCID}_{50}\right)$ from pools of artificially contaminated blood serum until the dilution 1:160.
\end{abstract}

Key words: Cattle, bovine viral diarrhea, BVDV, RT-PCR, blood serum

\section{Introdução}

$\mathrm{O}$ vírus da diarréia viral bovina (bovine viral diarrhea virus -BVDV-) é o agente etiológico da diarréia viral bovina (BVD), enfermidade altamente contagiosa que, na fase aguda da doença, apresenta potencial imunodepressor (POTGIETER, 1988). A importância econômica dessa virose está diretamente relacionada aos aspectos produtivos e reprodutivos, que podem incluir queda na produção de leite, decréscimo na taxa de concepção, abortamento, mumificação fetal, nascimento de bezerro fraco e aumento da taxa de mortalidade neonatal (McGOWAN et al., 1993; DUBOVI, 1994).

Tanto em rebanhos bovinos de corte quanto de leite o BVDV está associado a várias manifestações clínicas como problemas reprodutivos e entéricos e/ ou respiratórios (PEDRIZET; REBHUN; DUBOVI, 1987). A infecção fetal por uma estirpe não-citopática (NCP) entre 40 e 120 dias de gestação resulta no nascimento de animal persistentemente infectado (PI), com indução de imunotolerância (BAKER, 1995), e constitui-se no elo da cadeia epidemiológica da infecção. Os animais PI quando expostos a uma nova população viral, representada pela estirpe citopática (CP) semelhante à estirpe NCP, desenvolvem a Doença das Mucosas que caracteriza-se por baixa morbidade e letalidade próxima a 100\% (HOWARD; BROWNLIE; CLARKE, 1987).

Na maioria dos países a BVD é endêmica, com soroprevalência de 60 a $85 \%$, com 1 a $2 \%$ de animais PI (HOUE, 1999). Estudos sorológicos têm demonstrado que o BVDV encontra-se amplamente difundido no rebanho bovino brasileiro (FIGUEIREDO et al., 1997; CANAL et al., 1998).

A ampla variedade de sinais clínicos, presentes também em outras doenças infecciosas e parasitárias, dificulta o diagnóstico clínico definitivo da BVD (BROCK, 1995; TAKIUCHI et al., 2005). Em rebanhos não vacinados contra o BVDV os métodos de diagnóstico sorológico tradicionais apenas indicam a presença da infecção, e não são utilizados para o estabelecimento do diagnóstico conclusivo. A soroconversão pós-vacinal em animais imunizados, com vacinas produzidas por metodologias convencionais, não permite diferenciar os resultados sorológicos positivos ocasionados pela infecção natural, daqueles resultantes da vacinação. A presença de animais PI também pode limitar a eficiência das técnicas sorológicas. Atualmente as técnicas mais utilizadas na detecção de anticorpos específicos para o BVDV incluem a soro- 
neutralização (SN) e os ensaios imunoenzimáticos (ELISA) (NISKANEN et al., 1989). Esses testes devem ser sensíveis o suficiente para evitar resultados falso-negativos, principalmente quando os títulos de anticorpos são baixos. Os sistemas de ELISA em uso atualmente no Brasil são compostos por kits comerciais importados e de alto custo. A SN é laboriosa, demanda estrutura de cultivo celular, e maior tempo para a conclusão dos resultados (SANDVICK, 1999).

Contudo, o diagnóstico da infecção ocasionada pelo BVDV somente poderá ser conclusivo a partir de métodos de diagnóstico etiológico. Para isto, podem ser utilizadas técnicas de isolamento viral em cultivo celular e microscopia eletrônica; identificação de antígenos virais pelas técnicas de imunofluorescência, imunoperoxidase e ELISA diretos; e identificação do genoma viral por meio de métodos moleculares como a hibridização e a reação em cadeia da polimerase, precedida de transcrição reversa (RT-PCR) (ROBERTS et al., 1991).

O isolamento viral em cultivo celular é a técnica rotineiramente empregada, porém, esse método requer a manutenção de linhagens celulares tornando o processo laborioso, demorado e de alto custo. A exigência da viabilidade da partícula viral, e conseqüentemente da sua infecciosidade, constitui outro inconveniente do isolamento viral. Os sistemas de ELISA também podem ser empregados para a detecção do BVDV e apresentam como vantagem, a não exigência de culturas celulares, além da possibilidade da conclusão dos resultados em poucas horas (NISKANEN et al., 1989). Como desvantagem, os sistemas de ELISA são empregados para o diagnóstico do BVDV em amostras biológicas provenientes de um único animal. A dependência de kits comerciais importados aumenta consideravelmente o custo por reação, praticamente inviabilizando a sua aplicação na triagem de rebanhos bovinos para a identificação de animais PI.
Os métodos de diagnóstico molecular, particularmente a RT-PCR, estão sendo universalmente adotados para o diagnóstico etiológico de diversas viroses animais (BÉLAK; BALLAGIPORDÁNY, 1993). As principais vantagens dessa técnica incluem a rapidez na obtenção dos resultados, a não exigência da infecciosidade da partícula viral e, quando devidamente padronizada, as altas taxas de sensibilidade e especificidade (McPHERSON; TAYLOR; QUIRKE, 1994; TAKIUCHI et al., 2003, 2005). A aplicação da RT-PCR em material biológico constituído por pools de amostras clínicas colhidas de vários animais facilita o rastreamento da infecção em rebanhos bovinos, além de diminuir o custo do diagnóstico.

Considerando que a identificação de animais PI, bem como a sua eliminação, constitui uma das principais medidas para a profilaxia e controle da BVD, o presente trabalho teve como objetivo otimizar e avaliar a RT-PCR para a realização do diagnóstico etiológico do BVDV em pools de amostras clínicas constituídas por sangue total ou soro sangüíneo, artificialmente contaminados com a estirpe NADL do BVDV.

\section{Material e Métodos}

\section{Virus e células}

A estirpe citopática NADL do BVDV foi produzida em células MDBK (Madin Darby bovine kidney) mantidas em meio Dulbecco modificado (DMEM, Gibco BRL, EUA) suplementado com 7\% de soro fetal bovino (SFB, Gibco, BRL, EUA) livre de micoplasmas e vírus, $55 \mathrm{mg} / \mathrm{mL}$ de gentamicina (Sigma ${ }^{\circledR}$ Co., EUA) e $2,5 \mathrm{mg} / \mathrm{mL}$ de anfotericina B $\left(\right.$ Sigma $^{\circledR}$ Co., EUA). Para a produção do BVDV em cultivo celular a concentração do SFB presente no meio de cultura celular D-MEM foi reduzida para $1 \%$. O título viral presente na suspensão foi calculado em dose infecciosa $50 \%$ para cultura de tecidos $(50 \%$ tissue culture infective doses - $\mathrm{TCID}_{50}-$ ), segundo Reed e Muench (1938). 


\section{Soro-neutralização}

A deteç̧ão de anticorpos contra o BVDV, após prévia inativação do soro a $56^{\circ} \mathrm{C} / 30 \mathrm{~min}$, foi realizada pela microtécnica de $\mathrm{SN}$, com incubação vírus/soro por $1 \mathrm{~h} \mathrm{a} 37^{\circ} \mathrm{C}$ em atmosfera de $5 \%$ de $\mathrm{CO}_{2}$. Os experimentos foram realizados em células MDBK mantidas a $37^{\circ} \mathrm{C}$ em meio D-MEM suplementado com gentamicina e anfotericina B e 10\% de SFB. Para a realização da $\mathrm{SN}$ a concentração do $\mathrm{SFB}$ foi reduzida para $1 \%$. Em todos os experimentos foram incluídos controles de vírus $\left(100,10\right.$ e 1 TCID $_{50}$ ); soros positivos e negativos, além de SFB isento de anticorpos para o BVDV. Todas as amostras de soro incluídas no trabalho foram analisadas quanto ao grau de toxicidade para cultivo celular. Os soros foram considerados tóxicos e, conseqüentemente descartados do experimento, quando determinavam lise celular nas cavidades onde não havia o vírus padrão. $\mathrm{A} S \mathrm{SN}$ foi realizada em microplacas de 96 cavidades (NUNCLON $\left.{ }^{\circledR}, \mathrm{EUA}\right)$ com $4 \times 10^{4}$ células/cavidade e os soros testados até a diluição de 1:64. Foram consideradas como positivas as amostras que inibiram 100\% do efeito citopático (ECP) de 100 $\mathrm{TCID}_{50}$ da estirpe NADL do BVDV a partir da diluição 1:8 após $72 \mathrm{~h}$ de incubação a $37^{\circ} \mathrm{C}$ em atmosfera de $5 \%$ de $\mathrm{CO}_{2}$.

\section{Amostras clínicas}

Inicialmente, alíquotas de $900 \mu \mathrm{L}$ de soro sangüíneo e de sangue total, provenientes de bovinos soronegativos para o BVDV pela SN, foram artificialmente contaminadas com $100 \mu \mathrm{L}$ da estirpe NADL do BVDV com o título de $10^{3,56} \mathrm{TCID}_{50}$. A partir dessas amostras, foram realizadas diluições seriadas (1:5 - 1:160) na base 2 utilizando como diluente pools de sangue total ou soro sangüíneo, também provenientes de bovinos isentos de anticorpos para o BVDV.

\section{Extração do Ácido Nucléico}

Alíquotas de $500 \mu \mathrm{L}, 300 \mu \mathrm{L}, 100 \mu \mathrm{L}$ e $50 \mu \mathrm{L}$ das diluições de sangue total e soro sangüíneo contaminadas com o BVDV, com e sem a adição de tampão de lise: i) $1 \%$ Nonidet P40, 10 mM EDTA, $20 \mathrm{mM}$ Tris-HCl e incubação por $10 \mathrm{~min}$ a temperatura ambiente; ou ii) $0,5 \% \mathrm{SDS}, 1 \%$ Proteinase K (Invitrogen ${ }^{\mathrm{TM}}$, Life Technologies, EUA) e incubação por $30 \min$ a $56^{\circ} \mathrm{C}$ ), foram submetidas à extração do ácido nucléico por quatro métodos: i) fenol / clorofórmio / álcool isoamílico (25:24:1), ii) sílica / isotiocianato de guanidina, iii) combinação dos métodos fenol / clorofórmio / álcool isoamílico e sílica / isotiocianato de guanidina e iv) TRIzol ${ }^{\mathrm{TM}}$ (Invitrogen ${ }^{\mathrm{TM}}$, Life Technologies, EUA).

Os métodos do fenol / clorofórmio / álcool isoamílico e da sílica / isotiocianato de guanidina foram, respectivamente, realizados de acordo com Sambrook, Fritsch e Maniatis (1989) e Boom et al (1990). A extração do RNA empregando o TRIzol ${ }^{\mathrm{TM}}$ foi realizada segundo as instruções do fabricante. A combinação dos métodos fenol / clorofórmio / álcool isoamílico e sílica / isotiocianato de guanidina foi utilizada de acordo com Alfieri et al (2004), com pequenas modificações. Inicialmente as amostras foram tratadas com igual volume de fenol/ clorofórmio / álcool isoamílico (25:24:1), agitadas em vórtex e aquecidas em banho-maria a $56^{\circ} \mathrm{C} / 15 \mathrm{~min}$. Em seguida, os tubos foram centrifugados a 10.000 $\mathrm{x} \mathrm{g} / 10$ min e a fase aquosa foi processada em sílica / isotiocianato de guanidina, de acordo com Boom et al (1990). Ao final, o ácido nucleico foi eluído em 50 $\mu \mathrm{L}$ de água ultra-pura (MilliQ ${ }^{\circledR}$ ) autoclavada e mantido a $-20^{\circ} \mathrm{C}$ até o uso. Em todos os procedimentos de extração do RNA foram incluídas alíquotas de água ultra-pura autoclavada como controle negativo e a estirpe NADL do BVDV como controle positivo.

\section{Oligonucleotídeos iniciadores (Primers)}

Nos experimentos de otimização da RT-PCR foram utilizados dois pares de oligonucleotídeos iniciadores (primers). O primeiro par de primers, descrito por Weinstock, Bhudevi e Anthony (2001), denominado 103 sense (5' tag cca tgc cct tag tag gac 3' - nt 103-124) e 372 anti-sense (5' act cca 
tgt gec atg tac agc 3' - nt 372-392) foi desenhado a partir da seqüência da região 5 ' não-traduzida (5'UTR) e aplifica um produto de 290 pares de base (pb). O segundo par de primers avaliado, denominado panpestivírus e descrito por Vilcek et al. (1994), é representado pelo primer 324 sense (5', atg ccc wta gta gga cta gca 3 ' onde $\mathrm{W}=\mathrm{A}$ ou $\mathrm{T}$, nt 108-128) e 326 anti-sense (5' tca act cca tgt gcc atg tac 3' - nt 375-395) e amplifica um produto de $288 \mathrm{pb}$ do mesmo gene.

\section{Transcrição reversa $-R T$}

Para a realização da $\mathrm{RT}$ foram avaliados diferentes volumes $(1 \mu \mathrm{L}, 3 \mu \mathrm{L}, 5 \mu \mathrm{L}$ e $9 \mu \mathrm{L})$ do RNA extraído, 20 pmol do primer anti-sense (372 ou 326), 0,25 mM de cada dNTP (Invitrogen ${ }^{\mathrm{TM}}$, Life Technologies, EUA) e dois tipos de tampões: i) 1xRTbuffer (Invitrogen ${ }^{\mathrm{TM}}$, Life Technologies, EUA) (50 $\mathrm{mM}$ Tris- $\mathrm{HCl} \mathrm{pH} 8,4 ; 75 \mathrm{mM} \mathrm{KCl} ; 3 \mathrm{mM} \mathrm{MgCl}_{2} ; 1$ $\mathrm{mM}$ dithiotreitol) ou ii) 1xPCR buffer (20 mM Tris$\mathrm{HCl} \mathrm{pH} 8,4 ; 50$ mM KCl - Invitrogen ${ }^{\mathrm{TM}}$, Life Technologies, EUA) com concentrações crescentes de $\mathrm{MgCl}_{2}(1,5 ; 2,0 ; 2,5$ e 3,0 mM). A enzima transcriptase reversa M-MLV (Invitrogen ${ }^{\mathrm{TM}}$, Life Technologies, EUA) foi incluída na reação nas concentrações de 60, 120 ou 200 unidades. O volume final de $20 \mu \mathrm{L}$ por reação foi obtido pela adição de água ultra-pura autoclavada. Anteriormente à adição dos reagentes (RT-MIX) o RNA extraído foi desnaturado a $97^{\circ} \mathrm{C}$ ou $65^{\circ} \mathrm{C} / 5 \mathrm{~min}$. A síntese do cDNA foi realizada em termociclador (PTC-200, MJ Research Co., EUA) sob diferentes condições de temperatura e tempo: i) $37^{\circ} \mathrm{C} / 1 \mathrm{~h}$, ou ii) $42^{\circ} \mathrm{C} / 30$ min. Posteriormente a enzima M-MLV foi inativada a $95^{\circ} \mathrm{C} / 5 \mathrm{~min}$.

\section{Reação em cadeia pela polimerase - PCR}

A PCR foi realizada em uma solução contendo 5 mL de cDNA e $45 \mu \mathrm{L}$ de PCR-MIX constituído por 20 pmol de cada primer (103 / 372 ou 324 / 326), 0, 1 mM de cada dNTP, 2,5 unidades de Taq DNA polimerase recombinante (Invitrogen ${ }^{\mathrm{TM}}$, Life Technologies, BR), 1xPCR buffer (20 mM Tris- $\mathrm{HCl}$ pH 8,4 e $50 \mathrm{mM}$ de $\mathrm{KCl}), 1,5 \mathrm{mM} \mathrm{MgCl}_{2}$ e água ultrapura autoclavada para o volume final de $50 \mu \mathrm{L}$. O cDNA foi pré-desnaturado a $94^{\circ} \mathrm{C} / 4$ min e mantido em banho de gelo até a adição dos reagentes. A amplificação foi realizada em termociclador nas seguintes condições de tempo e temperatura para os primers 103 / 372: i) uma etapa de $4 \mathrm{~min} / 94^{\circ} \mathrm{C}$; ii) 35 ciclos de $1 \mathrm{~min} / 94^{\circ} \mathrm{C}$ (desnaturação), $30 \mathrm{~s} \mathrm{em}$ gradiente de temperatura $57^{\circ} \mathrm{C}$; $58^{\circ} \mathrm{C} ; 59^{\circ} \mathrm{C} ; 62^{\circ} \mathrm{C}$ ou $65^{\circ} \mathrm{C}$ (anelamento) e $1 \mathrm{~min} / 72^{\circ} \mathrm{C}$ (extensão) e iii) uma etapa de extensão final por 7 $\min / 72^{\circ} \mathrm{C}$. Para os primers 324 / 326 as condições das reações foram as seguintes: i) uma etapa de 2 $\min / 94^{\circ} \mathrm{C}$, ii) 40 ciclos de $1 \mathrm{~min} / 94^{\circ} \mathrm{C}, 1 \mathrm{~min} / 57^{\circ} \mathrm{C}$ e $2 \mathrm{~min} / 72^{\circ} \mathrm{C}$ e iii) uma etapa de extensão final por $7 \mathrm{~min} / 72^{\circ} \mathrm{C}$.

\section{Análise dos Produtos da RT-PCR}

Alíquotas com $10 \mu \mathrm{L}$ dos produtos da RT-PCR foram submetidas à eletroforese em gel de agarose a $2 \%$ com brometo de etídeo $(0,5 \mathrm{mg} / \mathrm{mL})$ em tampão TBE pH 8,4 (89 mM Tris; $89 \mathrm{mM}$ ácido bórico; 2 mM EDTA), sob voltagem constante (90V) durante aproximadamente $30 \mathrm{~min}$. O gel foi visualizado sob luz ultra-violeta (UV) e fotodocumentado em sistema digital (Electrophoresis Documentation and Analysis System 290, KODAK ${ }^{\circledR}$, New York, EUA).

\section{Perfil de restrição}

A confirmação do produto amplificado na RT-PCR foi obtida pela análise do perfil de restrição com as enzimas Hae III e Hinf I (Invitrogen ${ }^{\mathrm{TM}}$, Life Technologies, EUA), utilizadas de acordo com as instruções do fabricante. Os fragmentos gerados pela clivagem enzimática foram analisados por meio de eletroforese em gel de agarose a $2 \%$ com brometo de etídeo $(0,5 \mathrm{mg} / \mathrm{mL})$, visualizados sob luz UV e fotodocumentado. 


\section{Resultados e Discussão}

Entre as alternativas testadas para a detecção do RNA do BVDV em amostras clínicas representadas por pools de sangue total e de soro sangüíneo artificialmente contaminados, a que resultou na melhor amplificação de um produto com $290 \mathrm{pb}$, que foi facilmente visualizado em gel de agarose $2 \%$ com brometo de etídeo, empregou as seguintes condições: i) volume inicial da amostra clínica: $50 \mu \mathrm{L}$ de soro sangüíneo; ii) extração do ácido nucléico: método da sílica/ isotiocianato de guanidina, iii) transcrição reversa: $9 \mu \mathrm{L}$ do ácido nucléico extraído; 20 pmol do primer $372 ; 0,25 \mathrm{mM}$ de cada dNTP, 1xPCR buffer $(20 \mathrm{mM}$ Tris- $\mathrm{HCl} \mathrm{pH} 8,4$ e $50 \mathrm{mM} \mathrm{KCl}$ ), 1,5 mM MgCl 2,60 unidades da enzima transcriptase reversa M-MLV, desnaturação do RNA a $97^{\circ} \mathrm{C} / 4$ min e transcrição reversa a $42^{\circ} \mathrm{C} / 30$ min e iv) PCR: primers 103 / 372 (WEINSTOCK; BHUDEVI; ANTHONY, 2001) com temperatura de anelamento de $59^{\circ} \mathrm{C}$.

Entre os dois tipos avaliados de material clínico, artificialmente contaminados com a estirpe NADL do BVDV, o soro sangüíneo apresentou resultados positivos até a diluição 1:160 (Figura 1), enquanto que em amostras de sangue total somente foi possível positividade até a diluição 1:20. A menor sensibilidade do sistema utilizando sangue total como material clínico para a detecção do RNA do BVDV, em amostras constituídas por pool, pode ser justificada devido à presença de inibidores da PCR em sangue total como hemoglobina, DNA de leucócitos e a presença de hemólise (WILSON, 1997).

Em animais com quadro clínico de infecção aguda, e também naqueles persistentemente infectados, o BVDV pode ser encontrado tanto no interior de leucócitos quanto livre no sangue. Essa característica possibilita a utilização do soro como amostra biológica para a detecção do BVDV, além de apresentar como vantagem a eliminação de uma série de prováveis inibidores presentes no sangue total (BROCK, 1995). $\mathrm{O}$ sangue apresenta ainda como desvantagem a necessidade de ser processado rapidamente após a colheita, inviabilizando a estocagem por tempo prolongado. Em contrapartida, o soro pode ser estocado em temperatura de congelamento. Nas situações que necessitam o diagnóstico etiológico o rebanho bovino pode ser proveniente de regiões distantes do laboratório de diagnóstico, e fatores como transporte e conservação das amostras podem ser responsáveis pelo insucesso do diagnóstico. A possibilidade da conservação da amostra por congelamento, como no caso do soro sangüíneo, além de permitir a estocagem do material biológico por período de tempo superior ao sangue, determina ainda maior facilidade no transporte e dificulta a contaminação da amostra.

Devido ao excesso de proteínas presentes no soro, a extração do ácido nucléico pelos métodos do fenol / clorofórmio / álcool isoamílico, bem como a sua combinação com a sílica / isotiocianato de guanidina ocasionou, já na primeira etapa da extração, a formação de uma fase protéica muito espessa que praticamente determinou a eliminação da fase aquosa. Em ambos os métodos essa primeira fase é utilizada para a continuidade da extração, tanto para a precipitação com etanol quando utiliza-se o fenol / clorofórmio / álcool isoamílico isoladamente, quanto para a inclusão da sílica, quando emprega-se a combinação dos dois métodos. Com o método TRIzol ${ }^{\mathrm{TM}}$, também foram obtidos resultados positivos. Porém, além da menor sensibilidade, pois somente foi possível a amplificação do produto até a diluição de 1:20, a qualidade do produto final não foi adequada, sendo observados sinais de degradação do ácido nucléico e bandas extras. O método descrito por Boom et al. (1990) que utiliza uma matriz de sílica e o isotiocianato de guanidina proporcionou a amplificação do produto nas maiores diluições, até 1:160, além de melhor qualidade uma vez que não foram observados sinais de degradação do ácido nucléico e tão pouco a presença de bandas extras. O método da sílica/ isotiocianato de guanidina apresenta como vantagens adicionais, em relação aos anteriores, a facilidade e rapidez de execução e a não geração de resíduos tóxicos, uma vez que o isotiocianato de guanidina pode ser neutralizado com $10 \mathrm{M} \mathrm{NaOH}$ anteriormente ao descarte. $\mathrm{O}$ isotiocianato de guanidina é ainda uma potente nuclease e sua ação sobre RNAses protege o RNA fita simples do BVDV (FANSON; OSMACK; BISCEGLIE, 2000). 
A utilização do tampão da enzima M-MLV 1xRTbuffer (50 mM Tris-HCl pH 8,4; $75 \mathrm{mM} \mathrm{KCl;} 3 \mathrm{mM}$ $\mathrm{MgCl}_{2} ; 1 \mathrm{mM}$ dithiotreitol), bem como a temperatura e o tempo $\left(37^{\circ} \mathrm{C} / 1 \mathrm{~h}\right)$ ideais para a ação da enzima, preconizados pelo fabricante, gerou resultados inconsistentes como falso-negativos e resultados positivos com fraca intensidade. Como alternativa, optou-se por alterar a constituição do tampão da enzima para 1xPCR buffer $(20 \mathrm{mM}$ Tris- $\mathrm{HCl} \mathrm{pH}$ 8,4; $50 \mathrm{mM} \mathrm{KCl}$ ), utilizar o $\mathrm{MgCl}_{2}$ na concentração de $1,5 \mathrm{mM}$ e alterar as condições de temperatura e tempo de incubação para $42^{\circ} \mathrm{C} / 30 \mathrm{~min}$. Com esse novo protocolo para a transcrição reversa observouse repetibilidade nos resultados positivos, que caracterizaram-se pela amplificação de produtos específicos com forte intensidade em gel de agarose.

Com freqüência as técnicas de biologia molecular, como a RT-PCR, utilizam reagentes e tampões "prontos para o uso" que facilitam a execução da técnica, diminuindo a margem de erro gerada pela diversidade de reagentes incluídos na reação. Porém, variáveis como: i) tipo do ácido nucléico (RNA/DNA), ii) tamanho do produto amplificado, iii) porcentagem de C-G (citosina / guanina) no amplicon, iv) formação de hetero-duplex, e v) origem da amostra clínica analisada; podem interferir no resultado final da reação (ANDRE et al., 1995; HYNDMAN et al., 1998; LETELLIER; KERKHOFS, 2003).

Nesse trabalho ficou evidente a real necessidade da padronização dos reagentes incluídos na RT-PCR uma vez que a utilização de um tampão na reação de transcrição reversa, constituído pelos mesmos sais, porém em concentrações diferentes, além da alteração do tempo e temperatura da reação, proporcionaram resultados satisfatórios que permitiram a continuidade dos trabalhos.

Para a etapa da PCR os primers 103 / 372 descritos por Weinstock; Bhudevi; Anthony (2001) quando utilizados em temperatura de anelamento de $59^{\circ} \mathrm{C}$ determinaram resultados muito superiores aos primers 324 / 326, denominados panpestivirus e amplamente utilizados para o diagnóstico do BVDV.
Apesar de hibridizarem em posições muito próximas na região 5'-UTR, os primers 324 / 326 apresentaram resultados de baixa consistência quando foi reproduzida a metodologia proposta pelos autores que os descreveram. A sensibilidade da reação empregando esses primers também foi muito inferior em relação aos primers 103 / 372, que amplificaram o produto esperado (290 pb) em maior concentração, gerando bandas de maior intensidade de coloração em gel de agarose. Weinstock; Bhudevi; Anthony (2001), utilizaram a temperatura de anelamento de $62^{\circ} \mathrm{C}$ para os primers 103 e 372 . Porém, no presente estudo essa temperatura gerou resultados inconclusivos, ocasionando redução tanto na sensibilidade quanto na especificidade, com a amplificação de produtos inespecíficos. Após a realização da técnica em gradiente de temperatura de anelamento observou-se a amplificação do produto esperado em maior quantidade e melhor qualidade na temperatura de $59^{\circ} \mathrm{C}$. Esse resultado pode ter sido gerado pelo sistema empregado por Weinstock; Bhudevi; Anthony (2001), onde as reações de transcrição reversa e de PCR foram realizadas em apenas um passo (single step), com a utilização de kit (Gene Amp EZ rTth RNA PCR, Perkin-Elmer ${ }^{\mathrm{TM}}$, EUA). O sistema otimizado nesse estudo, conforme descrito anteriormente, foi idealizado em duas etapas (two steps), com as reações da transcrição reversa e da PCR realizadas individualmente.

A caracterização do produto com 290 pb da região 5'-UTR da estirpe NADL do BVDV, bem como da amostra de soro sangüíneo artificialmente contaminado na diluição 1:40, gerou fragmentos de 242 e 48 pb com a enzima Hae III. Conforme deduzido pela análise in silico, o produto não apresentou sítio de restrição para a enzima Hinf I (Figura 2).

Para o diagnóstico etiológico das várias formas de manifestação clínica da BVD, o isolamento viral em cultivo celular é considerado a técnica padrão. Entretanto, esse método de diagnóstico é laborioso, demorado, e nas infecções ocasionadas por estirpes NCP, que correspondem a 95\% das situações, a caracterização do isolamento viral somente pode ser obtida por meio do uso de técnicas complementares 
como a imunofluorescência ou a imunoperoxidase. Com isso, o diagnóstico definitivo, em raras ocasiões, pode ser obtido em período inferior a 15 dias (NISKANEN et al., 1989; EDWARDS, 1990).

Vários métodos de ELISA foram desenvolvidos com o objetivo principal de redução no período de tempo necessário para a conclusão de resultados, particularmente em estudos relativos à identificação de animais PI em rebanhos bovinos. Porém, o ELISA é realizado em amostras biológicas (soro sangüíneo, plasma ou sangue total) individuais o que aumenta o custo final do diagnóstico, podendo inclusive inviabilizar o seu uso em situações de rebanhos onde muitos animais devem ser avaliados (ROSSMANITH et al., 2001).

Para contornar os inconvenientes dos métodos de diagnóstico etiológico descritos anteriormente, a RT-PCR tem-se tornado uma ferramenta indispensável, particularmente devido a sua alta sensibilidade, que possibilita a detecção de seqüências genômicas mesmo em amostras nos quais os microrganismos encontram-se em título muito baixo, inativados ou mesmo em amostras altamente diluídas.

No presente trabalho a importância da otimização da RT-PCR, antes de sua utilização em larga escala como diagnóstico etiológico, ficou bem caracterizada.
O uso tanto do tampão da enzima transcriptase reversa M-MLV, fornecido pelo fabricante, quanto das condições de tempo e temperatura preconizadas para a enzima, geraram resultados com baixa repetibilidade e qualidade, além de falso-negativos. Após a introdução de modificações que envolveram, particularmente, a constituição do tampão, a concentração e as condições de tempo e temperatura de reação da enzima M-MLV obteve-se maior sensibilidade e qualidade das reações de amplificação.

A RT-PCR utilizando os primers descritos por Weinstock; Bhudevi; Anthony (2001) e otimizada nesse estudo demonstrou ser uma estratégia de diagnóstico etiológico do BVDV capaz de proporcionar resultados conclusivos em período de tempo inferior ao isolamento viral. Devido a maior sensibilidade, com relação aos métodos anteriormente descritos, a RT-PCR apresenta ainda a vantagem adicional de, além de poder ser utilizada em amostras individuais, ser realizada em soros sangüíneos na forma de pool, constituído por amostras provenientes de até 160 animais, proporcionando redução no custo final do diagnóstico. Essa estratégia facilita tanto o diagnóstico da forma aguda da infecção quanto a identificação de animais PI em grandes rebanhos, característica freqüente nos sistemas de produção, particularmente de corte, da bovinocultura brasileira.

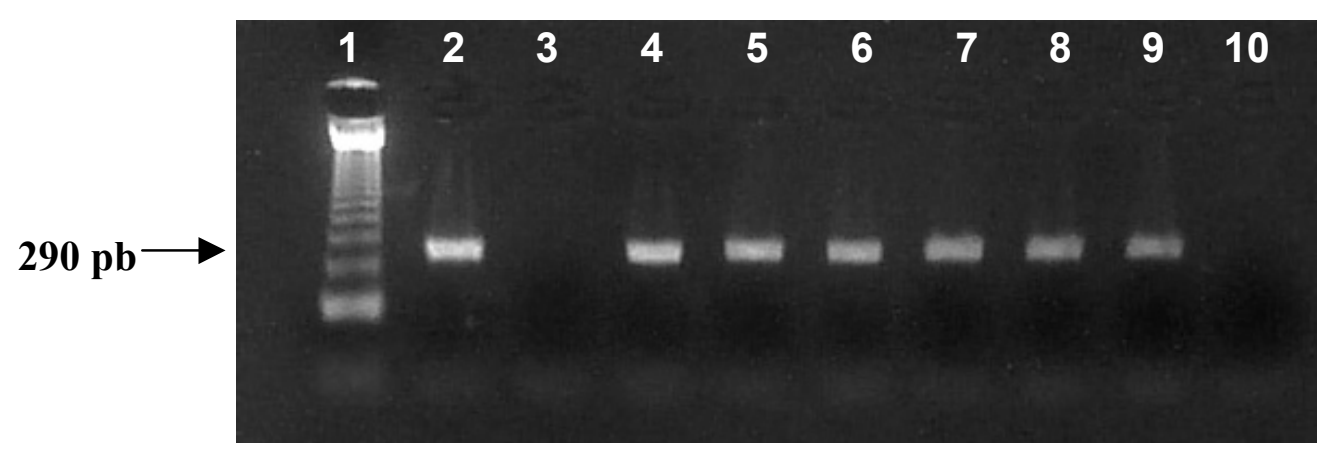

Figura 1. Análise por eletroforese em gel de agarose $2 \%$ com brometo de etídeo dos produtos ( $290 \mathrm{pb}$ ) amplificados pela RT-PCR em pools de soros sangüíneos bovino, artificialmente contaminados com a estirpe NADL do vírus da diarréia viral bovina (BVDV). Canaleta 1: marcador de tamanho molecular 123 pb ladder (Invitrogen ${ }^{\mathrm{TM}}$, Life Technologies, EUA); Canaleta 2: estirpe NADL do BVDV; Canaleta 3: soro sangüíneo proveniente de bovino soronegativo para o BVDV; Canaletas 4 a 9: diluições (1:5, 1:10, 1:20, 1:40, 1:80 e 1:160, respectivamente) de pools de soros sangüíneos artificialmente contaminados com a estirpe NADL do BVDV; Canaleta 10: água ultra-pura (MilliQ ${ }^{\circledR}$ ) autoclavada. 


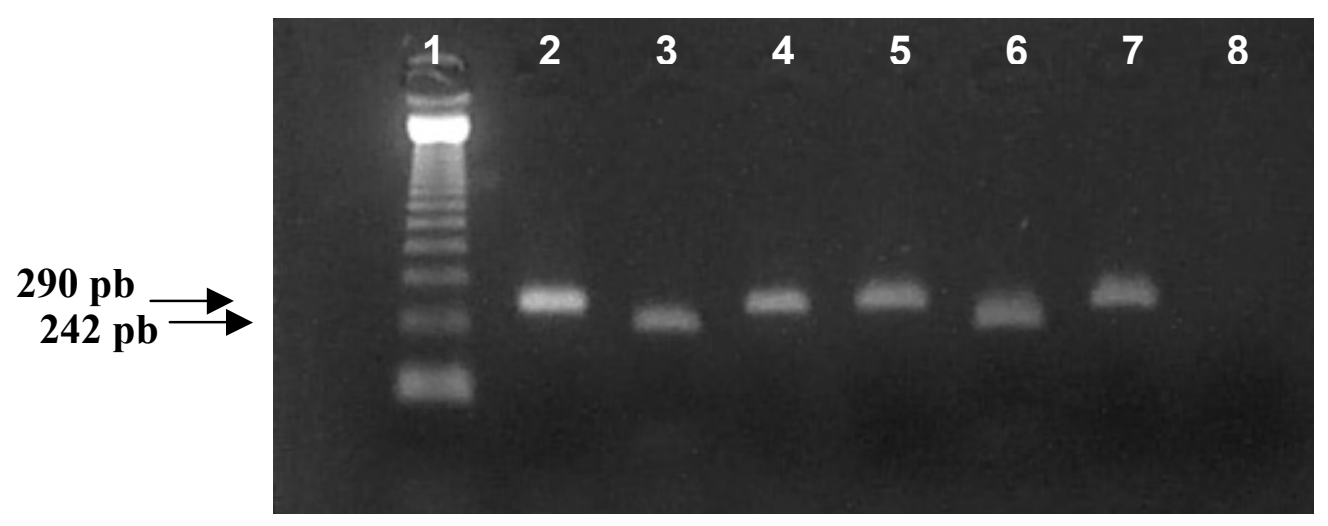

Figura 2. Eletroforese em gel de agarose $2 \%$ com brometo de etídeo dos produtos amplificados pela RT-PCR para a detecção da estirpe NADL do vírus da diarréia viral bovina (BVDV), analisados com enzimas de restrição Hae III e Hinf I. Canaleta 1: marcador de tamanho molecular 123 pb ladder (Invitrogen ${ }^{\mathrm{TM}}$, Life Technologies, EUA); Canaleta 2: estirpe NADL do BVDV; Canaletas 3 e 4: estirpe NADL do BVDV analisada com as enzimas Hae III e Hinf I respectivamente; Canaleta 5: diluição 1:40 do pool de soro sangüíneo artificialmente contaminado; Canaletas 6 e 7: diluição 1:40 de pool de soro sangüíneo artificialmente contaminado, analisado com as enzimas Hae III e Hinf I, respectivamente; Canaleta 8: água ultra-pura (MilliQ ${ }^{\circ}$ ) autoclavada.

\section{Agradecimentos}

Os recursos financeiros utilizados para a realização deste trabalho foram obtidos nas seguintes agências de fomento à pesquisa: CNPq, CAPES e Fundação Araucária (FAP/PR).

Alfieri, A.A. é bolsista de produtividade científica do $\mathrm{CNPq}$

\section{Referências}

ALFIERI, A. F.; ALFIERI, A. A.; BARREIROS, M. A. B.; LEITE, J. P. G.; RICHTZENHAIN, L. J. G and P genotypes of group A rotavirus strains circulating in calves in Brazil, 1996-1999. Veterinary Microbiology, Amsterdam, v. 99, p. 167-173, 2004.

ANDRE, L.; HAMEL, M.; DEANNE W.; NAYAR, G. P. S. Rapid detection of bovine viral diarrhea virus by using RNA extracted directly from assorted specimens and onetube reverse transcription PCR assay. Journal of Clinical Microbiology, Washington, v. 33, p. 287-291, 1995.

BAKER, J. C. The clinical manifestations of bovine viral diarrhoea infection. The Veterinary Clinics of North America, Food Animal Practice, Philadelphia, v. 11, p. 425-445, 1995.

BÉLAK, S.; BALLAGI-PORDÁNY. A. Application of the polymerase chain reaction (PCR) in veterinary diagnostic virology. Veterinary Research Communications, Amsterdam, v. 17, p. 55-72, 1993.
BOOM, R.; SOL, C. J. A.; SALIMANS, M. M. M.; JANSEN, C. L.; WERTHEIM DILLEN, P. M. E.; NOORDAA, J. Rapid and simple method for purification of nucleic acids. Journal of Clinical Microbiology, Washington, v. 28, n. 3, p. 495503, 1990.

BROCK, K. V. Diagnosis of bovine viral diarrhea virus infections. The Veterinary Clinics of North America, Food Animal Practice, Philadelphia, v. 11, p. 549-561, 1995.

CANAL, C. W.; STRASSER M.; HERTIG, C.; MASUDA, A. E.; PETERHANS, E. Detection of antibodies to bovine viral diarrhea virus (BVDV) and characterization of genomes of BVDV from Brazil. Veterinary Microbiology, Amsterdam, v. 63, p. 85-97, 1998.

DUBOVI, E. J. Impact of bovine diarrhea virus on reproductive performance in cattle. The Veterinary Clinics of North America, Food Animal Practice, Philadelphia, v. 10, p. 503-514, 1994.

EDWARDS, S. The diagnosis of bovine virus diarrhoeamucosal disease in cattle. International Office des Epizooties, Paris, v. 9, p. 115-130, 1990.

FANSON, B. G.; OSMACK, P.; BISCEGLIE, A. M. D. A comparison between the phenol-chloroform method of RNA extraction and the QIAamp viral RNA kit in the extraction of hepatitis $\mathrm{C}$ and $\mathrm{GB}$ virus-C / hepatitis $\mathrm{G}$ viral RNA from serum. Journal of Virological Methods, Amsterdam, v. 89, p. 23-27, 2000.

FIGUEIREDO, H. C. P.; VIEIRA, P. R.; LAGE, A. P.; LEITE, R. C. Prevalência de anticorpos contra o vírus da diarréia bovina a vírus em Minas Gerais, Brasil. Revista Brasileira de Reprodução Animal, Belo Horizonte, v. 21, p. 11-15, 1997. 
HOUE, H. Epidemiological features and economical importance of bovine virus diarrhea virus (BVDV) infections. Veterinary Microbiology, Amsterdam, v. 64, p. 89-107, 1999.

HOWARD, C. J.; BROWNLIE, J.; CLARKE, M. C. Comparison by the neutralization assay of pairs of noncytopathogenic and cytopathogenic strains of bovine virus diarrhoea virus isolated from cases of mucosal disease. Veterinary Microbiology, Amsterdam, v. 13, p. 361-869, 1987.

HYNDMAN, L.; VILCEK, S.; CONNER, J.; NETTLETON, P. F. A novel nested reverse transcription PCR detects bovine viral diarrhoea virus in fluids from aborted fetuses. Journal of Virological Methods, Amsterdam, v. 71, p. 6976, 1998.

LETELLIER, C.; KERKHOFS, P. Real-time PCR for simultaneous detection and genotyping of bovine viral diarrhea virus. Journal of Virological Methods, Amsterdam, v. 114, p. 21-27, 2003.

McGOWAN, M. R.; KIRKLAND, P. D.; RICHARDS, S. G. E.; LITTLEJOHNS, I. R. Increased reproductive losses in cattle infected with bovine pestivirus around the time of insemination. Veterinary Record, London, v. 133, p. 3943, 1993.

McPHERSON, Q. P.; TAYLOR, G. R.; QUIRKE, P. PCR $a$ pratical approach. Oxford: Information Press, 1994, 247 p.

NISKANEN, R.; ALENIUS, S.; LARSSON, B.; JUNTTI, N. Evaluation of an enzyme-linked immunosorbent assay for detection of antibodies to bovine virus diarrhoea virus in milk. Journal of Veterinary Medicine Séries B, Berlin, v. 36, p. 113-118, 1989.

PEDRIZET, J. A.; REBHUN, W. C.; DUBOVI, E. J. Bovine viral diarrhoea: clinical syndromes in dairy herds. Cornell Veterinarian, Ithaca, v. 77, p. 46-74, 1987

POTGIETER, L. N. D. Immunosuppression in cattle as a result of bovine diarrhea virus-infection. Agri-Practice. Santa Bárbara, v. 9, p. 7-14, 1988.

REED, R. H.; MUENCH, H. A single method of estimating fifty percent end points. American Journal of Hygiene, Baltimore, v. 27, p. 493-497, 1938.
ROBERTS, K. L.; COLLINAS, J. K.; CARMAN, J.; BLAIR, C. D. Detection of cattle infected with bovine viral diarrhea virus using nucleic acid hybridization. Journal of Veterinary Diagnostic Investigation, Columbia, v. 3, p. 10-15, 1991.

ROSSMANITH, W.; VILCEK, S.; WENZL, H.; ROSSMANITH, E.; LOITSCH, A.; DURKOVIC, B.; STROJNY, L.; PATON, D. J. Improved antigen and nucleic acid detection in a bovine virus diarrhoea eradication program. Veterinary Microbiology, Amsterdam, v. 81, p. 207-218, 2001.

SAMBROOK, J.; FRITSCH, E. F. MANIATIS, T. Molecular cloning: a laboratory manual. 2. ed. Cold Spring Harbor: Cold Spring Harbor Laboratory Press, 1989.

SANDVICK, T. Laboratory diagnostic investigations for bovine viral diarrhea virus infections in cattle. Veterinary Microbiology, Amsterdam, v. 64, p. 123-134, 1999.

TAKIUCHI, E.; MÉDICI, K. C.; ALFIERI, A. F.; ALFIERI, A. A. Otimização da reação em cadeia pela polimerase (Semi Nested-PCR) para a detecção do herpesvírus bovino tipo 1 em fragmentos de órgãos fetais e em sêmen de bovinos naturalmente infectados. Semina. Ciências Agrárias, Londrina, v. 24, p. 43-56, 2003.

TAKIUCHI, E.; MÉDICI, K. C.; ALFIERI, A. F.; ALFIERI, A. A. Bovine herpesvirus type 1 abortions detected by a semi nested-PCR in Brazilian cattle herds. Research in Veterinary Science, London, v. 78, n. 4, p. (prelo), 2005.

VILCEK, S.; HERRING, J. A.; NETTLETON, P. F.; LOWINGS, J. P.; PATON, D. J. Pestiviruses isolated from pigs, cattle and sheep can be allocated into at least three genogroups using polymerase chain reaction and restriction endonuclease analysis. Archives of Virology, New York, v. 136, p. 309-323, 1994.

WEINSTOCK, D.; BHUDEVI, B.; ANTHONY, E. C. Singletube single-reverse transcriptase PCR assay for detection of bovine viral diarrhea virus in pooled bovine serum. Journal of Clinical Microbiology, Washington, v. 39, p. 343-346, 2001.

WILSON, I. G. Inhibition and facilitation of nucleic acid amplification. Applied and Environmental Microbiology, Washington, v. 63, p. 3741-3751, 1997. 